\title{
Beneficial effect of recombinant human growth hormone on the intestinal mucosa barrier of septic rats
}

\section{C. $\mathrm{Yi}^{1}$, Y. $\mathrm{CaO}^{2}$, S.R. Wang ${ }^{2}$, Y.Z. Xu' ${ }^{2}, H$. Huang ${ }^{2}$, Y.X. Cui ${ }^{1}$ and Y. Huang ${ }^{2}$}

\author{
${ }^{1}$ Cancer Center, West China Hospital, ${ }^{2}$ Department of Pathophysiology, \\ West China School of Preclinical Sciences and Forensic Medicine, \\ Sichuan University, Chengdu, China
}

\section{Correspondence \\ Y. Huang \\ Department of Pathophysiology \\ West China School of Preclinical \\ Sciences and Forensic Medicine \\ Sichuan University \\ Chengdu 610041 \\ China \\ Fax: +86-028-8550-3204 \\ E-mail: huangying68@163.com \\ Research supported by Foundation of Applied Basic Research of the Science and Technology Bureau of Sichuan Province, China (No. 03JY029-072-1).}

Received January 30, 2006 Accepted November 13, 2006

\begin{abstract}
The objective of the present study was to investigate the effects of recombinant human growth hormone (rhGH) on the intestinal mucosa barrier of septic rats and explore its possible mechanism. Female Sprague-Dawley rats were randomized into three groups: control, Escherichia coli-induced sepsis (S) and treatment (T) groups. Groups $\mathrm{S}$ and $\mathrm{T}$ were subdivided into subgroups $1 \mathrm{~d}$ and $3 \mathrm{~d}$, respectively. Expression of liver insulin-like growth factor-1 (IGF-1) mRNA, Bcl2 and Bax protein levels and the intestinal $\mathrm{Bax} / \mathrm{Bcl}-2$ ratio, and plasma GH and IGF-1 levels were determined. Histological examination of the intestine was performed and bacterial translocation was determined. rhGH significantly attenuated intestinal mucosal injuries and bacterial translocation in septic rats, markedly decreased Bax protein levels, inhibited the decrease of Bcl-2 protein expression and maintained the $\mathrm{Bax} / \mathrm{Bcl}-2$ ratio in the intestine. rhGH given after sepsis significantly improved levels of plasma GH (T1d: $1.28 \pm 0.24$; T3d: $2.14 \pm 0.48 \mu \mathrm{g} / \mathrm{L} v s$ S1d: $0.74 \pm 0.12$; S3d: $0.60 \pm 0.18 \mu \mathrm{g} / \mathrm{L} ; \mathrm{P}<0.05)$ and IGF-1 (T1d: $168.94 \pm 65.67$; T3d: $201.56 \pm 64.98 \mu \mathrm{g} / \mathrm{L}$ vs S1d: $116.72 \pm 13.96$; S3d: $107.50 \pm 23.53 \mu \mathrm{g} / \mathrm{L} ; \mathrm{P}<0.05)$ and expression of liver IGF-1 mRNA (T1d: $0.98 \pm 0.20$; T3d: $1.76 \pm 0.17$ vs S1d: 0.38 \pm 0.09 ; S3d: $0.46 \pm 0.10 ; \mathrm{P}<0.05)$. These findings indicate that treatment with rhGH had beneficial effects on the maintenance of the integrity of the intestinal mucosa barrier in septic rats.
\end{abstract}

\section{Key words}

- Intestinal mucosa barrier

- Growth hormone

- Sepsis

- Insulin-like growth factor-1

- Apoptosis

\section{Introduction}

The intestinal mucosa has metabolic, endocrine and immunologic functions and serves as a major local defense barrier, preventing translocation of bacteria and endotoxins from the gut to extraintestinal tissues and blood (1). It has been shown that impairment of the intestinal mucosa barrier plays a critical role in the initiation of multiorgan dysfunction syndrome, as well as in multiple organ failure. Growth hormone $(\mathrm{GH})$, an anabolic hormone secreted by the anterior pituitary gland, is known to act on the gastrointestinal tract, maintaining the structure and function of intestinal mucosa (1). With a half-life of only $3 \mathrm{~h}, \mathrm{GH}$ action is mostly mediated by GH-dependent hepatic production of insulin-like growth factor-1 (IGF-1), which has been defined as an important in- 
testinal growth factor (2). Both animal and human studies have demonstrated that recombinant human growth hormone (rhGH) can enhance protein synthesis, promote tissue recovery, stimulate intestinal epithelial growth, etc. (3-5). However, the mechanism of the protective effect of rhGH on the intestinal mucosa barrier is not understood.

In the present study, sepsis was induced by intraperitoneal (ip) injection of Escherichia coli. The intestinal mucosa was examined histologically and bacterial translocation, Bcl-2 and Bax protein levels and the $\mathrm{Bax} / \mathrm{Bcl}-2$ ratio of the intestine were measured. Plasma GH and IGF-1 levels and expression of liver IGF-1 mRNA were also determined. Thus, the present study was undertaken to investigate the effects of rhGH treatment on the intestinal mucosa barrier of septic rats and to explore the possible mechanism involved.

\section{Material and Methods}

\section{Animal models and groups}

Female Sprague-Dawley rats weighing 200 to $240 \mathrm{~g}$ were obtained from the Animal Center of Sichuan University (Chengdu, China). The experimental protocol was approved by the Animal Care and Scientific Committee of Sichuan University. The rats were randomized into three groups: control group (group $\mathrm{C}, \mathrm{N}=8$ ), physiological saline alone, ip; sepsis group (group $\mathrm{S}, \mathrm{N}=17$ ), injected $i p$ with a bolus of ostrich strain $E$. coli suspension $\left(1 \times 10^{10} \mathrm{CFU} / \mathrm{L}, 15 \mathrm{~mL} / \mathrm{kg}\right.$, provided by the Department of Microbiology, West China School of Preclinical and Forensic Medicine, Sichuan University), followed by intramuscular injection of physiological saline, and treatment group (group $\mathrm{T}, \mathrm{N}=17$ ), which received a bolus administration of $E$. coli and was treated with an intramuscular injection of rhGH (Saizen, Serono Co., Geneva, Switzerland) (2.25 U $\mathrm{kg}^{-1}$ day $^{-1}$ ) once a day. Group S was subdi- vided into S1d $(\mathrm{N}=8)$ and $\mathrm{S} 3 \mathrm{~d}(\mathrm{~N}=9)$ subgroups receiving physiological saline for 1 day or daily for 3 days. Group $\mathrm{T}$ was subdivided into T1d $(\mathrm{N}=9)$ and T3d $(\mathrm{N}=8)$ subgroups receiving rhGH for 1 day or daily for 3 days.

\section{Measurement of GH and IGF-1 levels in plasma}

Rats were anesthetized with sodium pentobarbital $(15 \mathrm{~mL} / \mathrm{kg}$, ip $)$. Blood anticoagulated by heparin was harvested through a femoral arterial cannula and then centrifuged to collect plasma. Plasma GH and IGF-1 levels were determined by radioimmunoassay using a kit from Tianjin JiuDing Medicine Bio-Engineering Co., Ltd., Tianjin, China, for GH and a radioimmunoassay kit from Biocode-Hycel Company, Brussels, Belgium, for IGF-1.

\section{Observation of bacterial translocation}

Bacterial translocation is a phenomenon characterized by migration of bacteria through the intestinal wall into extra-intestinal tissues, so that bacteria that grow in blood cultures are the same as inside the bowel. In the present study, one drop of blood from the heart was spread on a glass slide and stained with Gram stain. Another $40-\mu \mathrm{L}$ heart blood sample was incubated on agar plates at $37^{\circ} \mathrm{C}$ and examined after $24 \mathrm{~h}$. Bacterial colony numbers were counted and the material was spread on a glass slide and stained with Gram stain. A bacteriologist observed the stained results under an oil microscope in a blind fashion.

\section{Histological examinations of the intestinal mucosa}

Two-centimeter long ileum specimens were fixed in neutral buffered formalin and embedded in paraffin. Sections $(5 \mu \mathrm{m})$ were used for standard histological staining with 
hematoxylin and eosin and then examined under a light microscope. A pathologist performed all pathologic examinations in a blind fashion. Length and width of intestinal mucosal villi were determined using BI-2000 medicine image analysis software (Chengdu Taimeng Technology Co., Ltd., Chengdu, China).

Immunohistochemical detection of Bcl-2 and Bax in the intestine

Immunohistochemical staining for Bcl-2 and Bax was performed by the streptavidinperoxidase method. Monoclonal Bcl-2 and Bax antibodies were purchased from Santa Cruz Company, Santa Cruz, CA, USA. For the negative control, phosphate-buffered solution was used instead of the primary antibody. Brown granules in the cytoplasm indicated positive expression of $\mathrm{Bcl}-2$ and Bax. These sections were analyzed by light microscopy and photographed. After photographic reconstruction of each tissue section, the photographs were scanned and digitized for computerized analysis with the Image-Pro plus 4.1 software (Media Cybernetics, Inc., Silver Spring, MD, USA). Integral optical density is reported as expression of Bcl-2 and Bax proteins.

\section{RT-PCR analysis for the expression of liver IGF-1 mRNA}

Total liver RNA was extracted with the Trizol reagent (Tiangen Biol-Tech Co., Ltd., Shanghai, China) and quantified spectrophotometrically. RT-PCR was run using a two-step method. Total RNA was used to synthesize cDNA with the MMuLV RT/ PCR reagent kit and then using PCR to amplify cDNA. Rat glyceraldehyde-3-phosphate dehydrogenase (GAPDH), the housekeeping gene, was used as internal control primer. Primer sequences were 5'-ATC ATG TCG TCT TCA CAT CTC TT-3' (upstream primer), 5'-CTA CAT TCT GTA GGT CTT
GTT TCC T-3' (downstream primer) for IGF1, and 5'-CCC ATC ACC ATC TTC CAG GA-3' (upstream primer), 5'-TGC TTC ACC ACC TTC TTG AT-3' (downstream primer) for GAPDH. The PCR products were a 376bp fragment for IGF-1 and a 574-bp fragment for GAPDH. PCR was performed in a $50-\mu \mathrm{L}$ reaction volume. A hot start was applied for $4 \mathrm{~min}$ at $94^{\circ} \mathrm{C}$. The amplification cycle (denaturation step at $94^{\circ} \mathrm{C}$ for $45 \mathrm{~s}$, an annealing step at $58^{\circ} \mathrm{C}$ for $45 \mathrm{~s}$ and an extension step at $72^{\circ} \mathrm{C}$ for $1 \mathrm{~min}$ ) was repeated 25 times. The amplified products of IGF-1 and GAPDH were separated by $1.2 \%$ agarose formaldehyde gel electrophoresis stained with ethidium and visualized with UV illumination. The electrophoresis photo was digitized, and IGF-1 and GAPDH band integrated optical density values were analyzed using a Bio-Rad image system (Hercules, CA, USA). Semiquantitative analysis of IGF1 mRNA was performed by comparison to GAPDH.

\section{Statistical analysis}

Data are reported as means \pm SD except for the rate of bacterial-positive blood smear. Bacterial-positive rates of blood smears were analyzed by the chi-square test. Other experimental results were analyzed statistically by the $q$ test. The results were analyzed using SPSS 11.0 software, with the level of significance set at $\mathrm{P}<0.05$.

\section{Results}

\section{Effects of rhGH on the histological appear-} ance of the intestine

In group $\mathrm{C}$, the intestinal mucosa structure remained intact, with villi arranged in an orderly manner. In group S, intestinal mucosal villi were edematous, markedly shortened, not uniform in length and arranged in a disorderly manner, and the epithelium was necrotic and markedly and flak- 
ing off. The lamina propria showed some edema accompanying inflammatory cell infiltration, with these changes being more marked in the S1d group. In group $\mathrm{T}$, the injuries to the intestinal mucosa were markedly attenuated, especially in the T3d group. In group $\mathrm{S}$, the length of intestinal mucosal

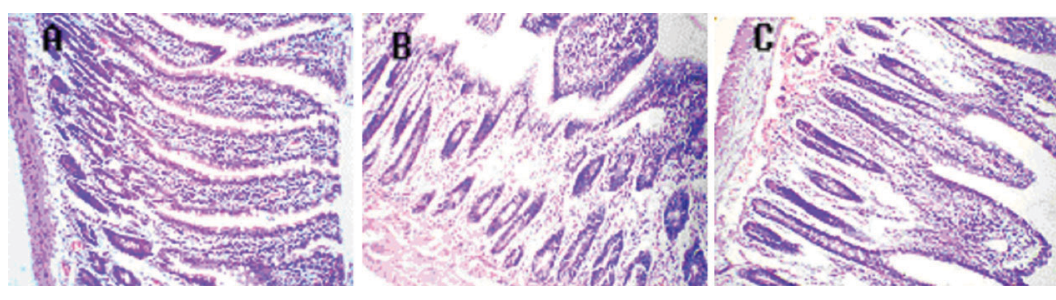

Figure 1. Histology of rat intestine in each group (hematoxylin-eosin; 200X). A, Control group: the intestinal mucosa structure remained intact and villi were arranged in an orderly manner; $B$, S1d group: intestinal mucosal villi were edematous, considerably shortened, not uniform in length and arranged in a disorderly manner. The epithelium was necrotic and seriously flaking off and the lamina propria showed edema accompanying inflammatory cell infiltration; $C$, T3d group: the injuries to the intestinal mucosa were markedly reduced.

Table 1. Comparison of length and width of intestinal mucosal villi in each group.

\begin{tabular}{lcc}
\hline Group & Length $(\mu \mathrm{m})$ & Width $(\mu \mathrm{m})$ \\
\hline Control $(\mathrm{N}=8)$ & $390.74 \pm 11.02$ & $81.36 \pm 4.69$ \\
S1d $(\mathrm{N}=8)$ & $181.86 \pm 28.75^{\star}$ & $114.76 \pm 13.30^{*}$ \\
S3d $(\mathrm{N}=9)$ & $196.59 \pm 24.43^{\star}$ & $120.63 \pm 17.29^{*}$ \\
T1d $(\mathrm{N}=9)$ & $256.56 \pm 26.17^{\star \#}$ & $80.81 \pm 13.40^{\#}$ \\
T3d $(\mathrm{N}=8)$ & $334.83 \pm 26.65^{\star \Delta}$ & $89.08 \pm 5.22^{\star}$ \\
\hline
\end{tabular}

Data are reported as means \pm SD. S1d and S3d are subgroups of the sepsis group receiving saline for 1 day or daily for 3 days, respectively. T1d and T3d are subgroups of the treatment group receiving rhGH for 1 day or daily for 3 days, respectively. ${ }^{*} \mathrm{P}<0.05$ compared to control; ${ }^{\#} \mathrm{P}<0.05$ compared to $\mathrm{S} 1 \mathrm{~d}$; ${ }^{\wedge} \mathrm{P}<0.05$ compared to S3d; ${ }^{\triangle} \mathrm{P}<0.05$ compared to $\mathrm{T} 1 \mathrm{~d}$ ( $q$ test).

Table 2. Comparison of bacterial-positive rate of blood smears and bacterial colony numbers in blood culture in each group.

\begin{tabular}{lcc}
\hline Group & $\begin{array}{c}\text { Bacterial-positive } \\
\text { rate of blood smear }\end{array}$ & $\begin{array}{c}\text { Number of bacterial colonies in } \\
\text { blood culture } \times 10^{6}(\mathrm{CFU} / \mathrm{L})\end{array}$ \\
\hline Control $(\mathrm{N}=8)$ & $0 / 8(0 \%)$ & 0 \\
S1d $(\mathrm{N}=8)$ & $8 / 8(100 \%)^{\star}$ & $14.14 \pm 1.79^{*}$ \\
S3d $(\mathrm{N}=9)$ & $9 / 9(100 \%)^{\star}$ & $6.68 \pm 1.32^{\star \#}$ \\
T1d $(\mathrm{N}=9)$ & $4 / 9(44.4 \%)^{\#}$ & $5.78 \pm 2.15^{\star \#}$ \\
T3d $(\mathrm{N}=8)$ & $3 / 8(37.5 \%)^{\star}$ & $0.95 \pm 0.17^{\star \Delta}$ \\
\hline
\end{tabular}

S1d and S3d are subgroups of the sepsis group receiving saline for 1 day or daily for 3 days, respectively. T1d and T3d are subgroups of the treatment group receiving rhGH for 1 day or daily for 3 days, respectively.

${ }^{*} \mathrm{P}<0.05$ compared to control; ${ }^{\mathrm{P}} \mathrm{P}<0.05$ compared to S1d; ${ }^{\wedge} \mathrm{P}<0.05$ compared to S3d;

${ }^{\wedge} \mathrm{P}<0.05$ compared to T1d (chi-square test). villi was clearly shortened and their width was clearly increased compared to group C. The length of intestinal mucosal villi was shorter in group $\mathrm{T}$ than in group $\mathrm{C}$, but was still significantly longer than that of group $\mathrm{S}$. There was no significant difference in the width of mucosal villi between group $\mathrm{T}$ and group C (see Table 1, Figure 1).

\section{Effects of rhGH on intestinal bacterial translocation}

Blood smear and bacterial culture were negative in group C. Blood smears from groups S1d and S3d showed 100\% bacterial positivity, whereas bacterial positivity was significantly lower in blood smears from groups T1d and T3d. Bacterial colony numbers were markedly lower in blood cultures of groups T1d and T3d compared with group $\mathrm{S}$ (see Table 2). Gram staining revealed $\mathrm{G}^{+}$ and $\mathrm{G}^{-}$bacteria in groups $\mathrm{S}$ and $\mathrm{T}$. Most bacteria were bacilli such as $E$. coli, etc. In addition, cocci were also found (see Figure 2).

Effects of rhGH on the levels of Bcl-2 and Bax proteins and the $\mathrm{Bax} / \mathrm{BCl}-2$ ratio in the intestine

As shown in Table 3 and Figure 3, Bcl-2 protein levels in the intestine of group $\mathrm{S}$ were obviously lower than in group $\mathrm{C}(\mathrm{P}<$ $0.05)$, and more so in group S1d. Bcl-2 protein in the intestine of group T1d was significantly lower than in group $\mathrm{C}$, but was markedly higher than in group $\mathrm{S}(\mathrm{P}<0.05)$, and $\mathrm{Bcl}-2$ protein expression showed no significant difference between groups $\mathrm{T} 3 \mathrm{~d}$ and $\mathrm{C}(\mathrm{P}>0.05)$. Compared with groups $\mathrm{C}$ and $\mathrm{T} 3 \mathrm{~d}$, Bax protein increased markedly in group S3d $(\mathrm{P}<0.05)$. Bax protein expression was clearly decreased in group T3d compared to groups $\mathrm{C}(\mathrm{P}<0.05)$ and $\mathrm{S}(\mathrm{P}<0.05)$. The $\mathrm{Bax} / \mathrm{Bcl}-2$ ratio was significantly higher in group $S$ than in group $\mathrm{T}(\mathrm{P}<0.05)$, and more so in group $\mathrm{S} 1 \mathrm{~d}$. The $\mathrm{Bax} / \mathrm{Bcl}-2$ ratio was clearly higher in group T1d than in group $\mathrm{C}$ 
$(\mathrm{P}<0.05)$ and was significantly higher than in group $\mathrm{S}(\mathrm{P}<0.05)$. The $\mathrm{Bax} / \mathrm{Bcl}-2$ ratio of group T3d returned to the level of group $\mathrm{C}(\mathrm{P}$ $>0.05)$.

\section{Effects of rhGH on plasma levels of $\mathrm{GH}$ and} IGF-1

Compared with groups $\mathrm{C}(1.18 \pm 0.28$ $\mu \mathrm{g} / \mathrm{L})$ and $\mathrm{T}(\mathrm{T} 1 \mathrm{~d}: 1.28 \pm 0.24 \mu \mathrm{g} / \mathrm{L} ; \mathrm{T} 3 \mathrm{~d}$ : $2.14 \pm 0.48 \mu \mathrm{g} / \mathrm{L})$, plasma $\mathrm{GH}$ levels declined markedly in groups $\mathrm{S} 1 \mathrm{~d}(0.74 \pm 0.12$ $\mu \mathrm{g} / \mathrm{L})$ and $\mathrm{S} 3 \mathrm{~d}(0.60 \pm 0.18 \mu \mathrm{g} / \mathrm{L} ; \mathrm{P}<0.05)$. Plasma GH levels were clearly higher in group T3d than in groups $\mathrm{C}(\mathrm{P}<0.05)$ and T1d $(\mathrm{P}<0.05)$. Plasma IGF-1 levels did not differ significantly between group $\mathrm{S}$ (S1d: $116.72 \pm 13.96 \mu \mathrm{g} / \mathrm{L} ; \mathrm{S} 3 \mathrm{~d}: 107.50 \pm 23.53$ $\mu \mathrm{g} / \mathrm{L})$ and group C $(106.63 \pm 18.75 \mu \mathrm{g} / \mathrm{L})$. Compared with groups C (106.63 \pm 18.75 $\mu \mathrm{g} / \mathrm{L})$ and $\mathrm{S}(\mathrm{S} 1 \mathrm{~d}: 116.72 \pm 13.96 \mu \mathrm{g} / \mathrm{L} ; \mathrm{S} 3 \mathrm{~d}$ :

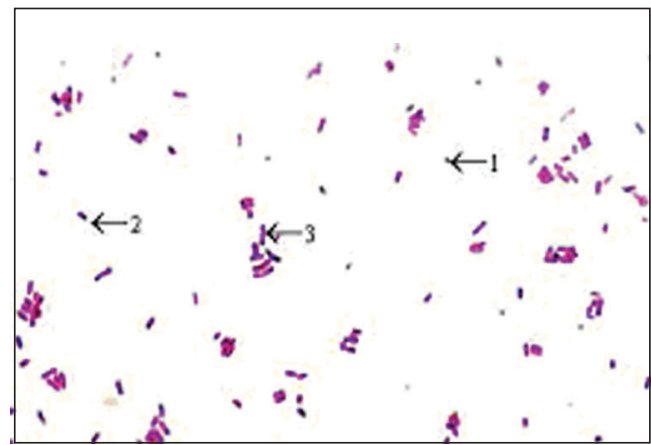

Figure 2. Gram staining of a smear of bacterial LB culture from group S1d (1000X). $\mathrm{G}^{+}$and $\mathrm{G}^{-}$bacteria were found. Arrow 1 indicates a coccus and arrows 2 and 3 indicate bacilli.
Table 3. Effects of recombinant human growth hormone on the levels of $\mathrm{Bcl}-2$ and Bax proteins and the Bax/ $\mathrm{Bcl}-2$ ratio in the intestine of septic rats.

\begin{tabular}{lrcc}
\hline Group & Bcl-2 & Bax & Ratio of Bax/Bcl-2 \\
\hline Control $(\mathrm{N}=8)$ & $4242 \pm 1213$ & $1582 \pm 252$ & $0.37 \pm 0.21$ \\
S1d $(\mathrm{N}=8)$ & $321 \pm 102^{*}$ & $1648 \pm 163$ & $5.13 \pm 0.34^{\star}$ \\
S3d $(\mathrm{N}=9)$ & $1873 \pm 171^{\star \#}$ & $2135 \pm 215^{\star \#}$ & $1.14 \pm 0.25^{\star \#}$ \\
T1d $(\mathrm{N}=9)$ & $2441 \pm 351^{\star \#}$ & $1486 \pm 145^{\#}$ & $0.61 \pm 0.11^{\star \#}$ \\
T3d $(\mathrm{N}=8)$ & $3628 \pm 664^{\star \star}$ & $1169 \pm 126^{\star \star \Delta}$ & $0.32 \pm 0.16^{\star}$ \\
\hline
\end{tabular}

Data are reported as mean \pm SD. S1d and S3d are subgroups of the sepsis group receiving saline for 1 day or daily for 3 days, respectively. T1d and T3d are subgroups of the treatment group receiving rhGH for 1 day or daily for 3 days, respectively.

${ }^{*} \mathrm{P}<0.05$ compared to control; $\# \mathrm{P}<0.05$ compared to S1d; ${ }^{\wedge} \mathrm{P}<0.05$ compared to S3d; ${ }^{\wedge} \mathrm{P}<0.05$ compared to $\mathrm{T} 1 \mathrm{~d}$ ( $q$ test).
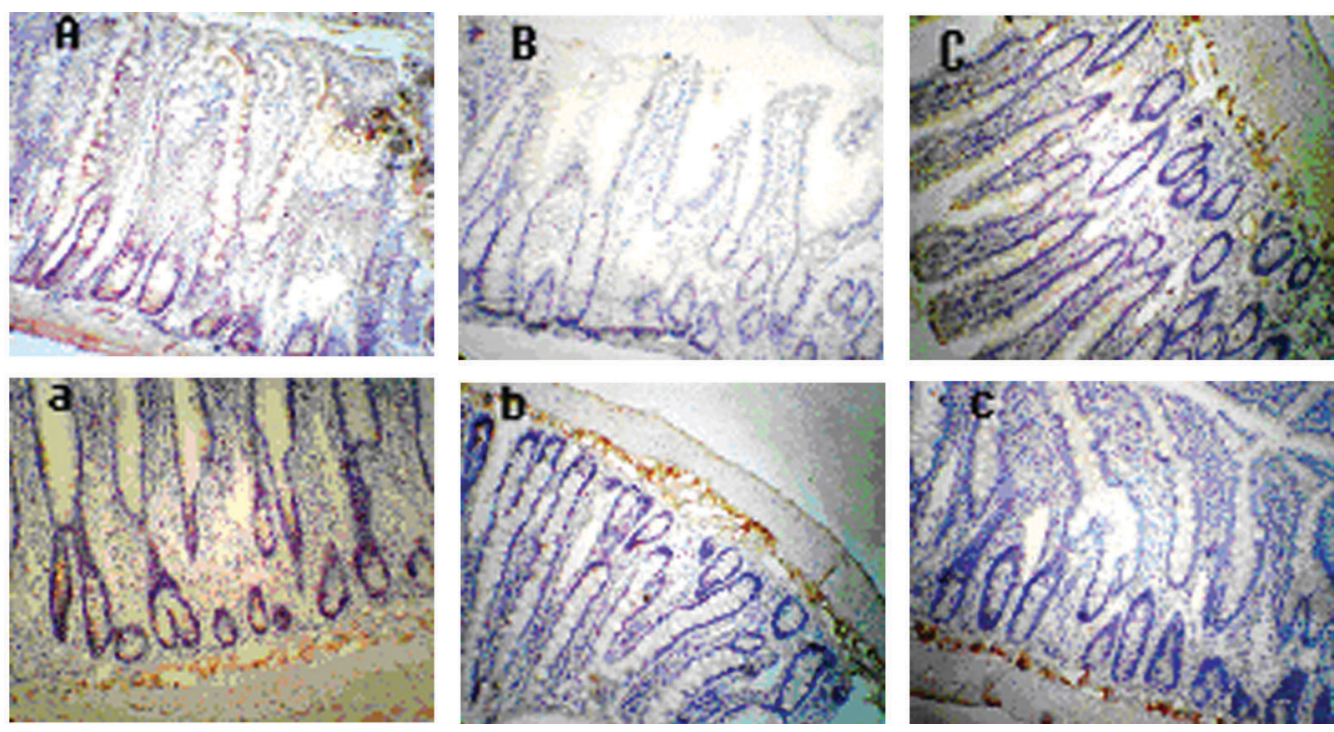

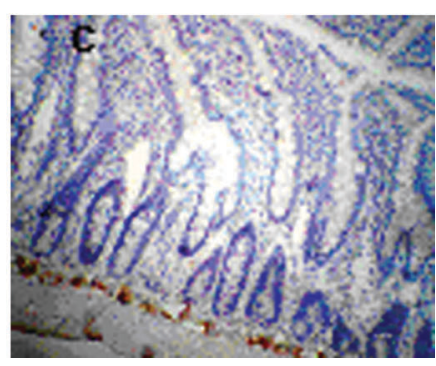

Figure 3. Bcl-2 and Bax expression in the intestine of each group (streptavidin-peroxidase; 200X). $A, B$, and $C$ illustrate $\mathrm{Bcl}-2$ expression in the control group, S1d group and T3d group, respectively. a, b and $c$ represent Bax expression in the control group, S1d group and T3d group, respectively. 
$107.50 \pm 23.53 \mu \mathrm{g} / \mathrm{L}$ ), plasma levels of IGF1 were clearly increase in group $\mathrm{T}(\mathrm{T} 1 \mathrm{~d}$ : $168.94 \pm 65.67 \mu \mathrm{g} / \mathrm{L} ; \mathrm{T} 3 \mathrm{~d}: 201.56 \pm 64.98$ $\mu \mathrm{g} / \mathrm{L})$ and especially in group $\mathrm{T} 3 \mathrm{~d}(\mathrm{P}<0.05)$.

\section{Effects of rhGH on the expression of liver IGF-1 mRNA}

Expression of liver IGF-1 mRNA was markedly lower in group S1d $(0.38 \pm 0.09)$ than in group $\mathrm{C}(0.64 \pm 0.08 ; \mathrm{P}<0.05)$. Expression of liver IGF-1 mRNA in group T was clearly higher than in groups $\mathrm{C}(\mathrm{P}<$ $0.05)$ and $S$ (S3d: $0.46 \pm 0.10 ; P<0.05)$, and more so in group T3d (see Figure 4).

\section{Discussion}

An important function of the intestinal mucosa barrier is to prevent translocation of bacteria/toxins into the circulation. The maintenance of function of the intestinal mucosa barrier depends upon the integrity of the structure and function of the intestinal mucosa. The present study showed that the integrity of the intestinal mucosa barrier was markedly compromised in septic rats. The results of Gram staining indicated that bacterial translocation occurred in the intestine of septic rats. rhGH administration reduced the injuries to the intestinal mucosa and bacterial translocation in septic rats, suggesting that treatment with rhGH had ben-

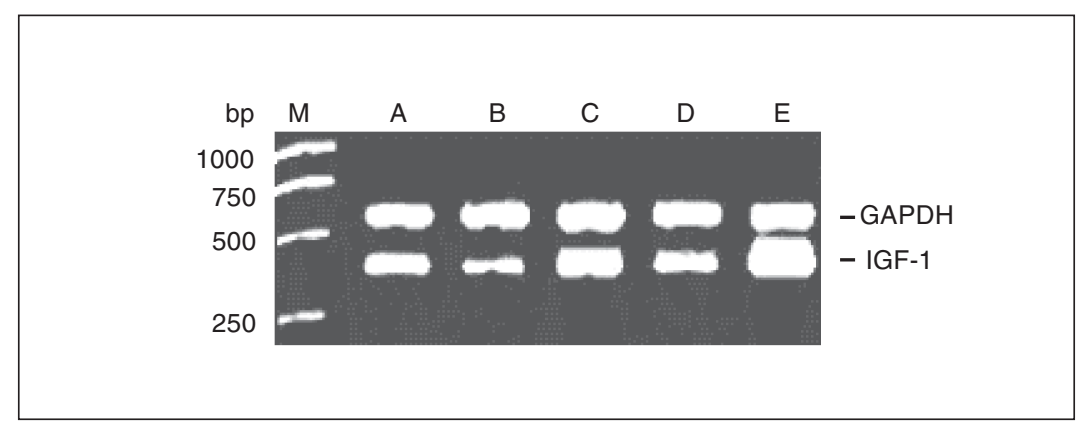

Figure 4. RT-PCR products of liver insulin growth factor 1 (IGF-1) on $1.2 \%$ agarose formaldehyde gel for each experimental group. Glyceraldehyde-3-phosphate dehydrogenase (GAPDH) was used as the internal control. Lane M, DNA marker DL 2,000 (TaKaRa Biotechnology Dalian Co., Ltd., Dalian, China); lane $A$, control group; lane B, S1d group; lane $C$, T1d group; lane $D$, S3d group; lane $E$, T3d group. eficial effects on the maintenance of the integrity of the intestinal mucosa barrier, as shown in the items below.

Inhibition of apoptosis. Bcl-2 is a typical apoptosis suppressor gene, while Bax is a gene that promotes apoptosis. The Bax/Bcl2 ratio determines whether apoptosis will occur (6). Our data showed that Bcl-2 protein expression was significantly decreased in the intestine of septic rats, while Bax protein expression and the $\mathrm{Bax} / \mathrm{Bcl}-2$ ratio were clearly increased in S group, suggesting that epithelial apoptosis was present in the intestinal mucosa of septic rats, in agreement with data reported by Coopersmith et al. (7). An increase of epithelial apoptosis reduces the cell population and causes separation of tight connections, which may be possible causes of impairment of the intestinal mucosa barrier. Baixeras et al. (8) have confirmed that rhGH treatment can inhibit apoptosis. Our results showed that rhGH treatment after sepsis could not only markedly decrease Bax protein levels but also inhibit the decrease of Bcl-2 protein expression and maintain the $\mathrm{Bax} / \mathrm{Bcl}-2$ ratio in the intestine, implying that rhGH inhibited apoptosis of the intestinal mucosa epithelium. To some extent, this may be useful to maintain the functions of the intestinal mucosa barrier and to alleviate bacterial translocation in septic rats.

Effects of rhGH on the GH/IGF-1 axis. Our data showed that plasma GH levels increased markedly during continuous rhGH administration to septic rats. GH receptors (GHRs) are extensively distributed in the intestinal mucosa. GH binding to GHRs through the ability of the intestinal mucosa to take up and utilize glutamine could promote growth differentiation and wound repair of the intestinal mucosa, ameliorate the impairment of the intestinal mucosa and maintain the structure and function of the intestinal mucosa barrier (9). The GH/IGF-1 axis is present in the body (10-14). GH binding to GHRs could increase IGF-1 lev- 
els, and the biological effects of $\mathrm{GH}$ are indirectly mediated by IGF-1 directly acting on target cells (15). IGF-1 is a polypeptide that affects the growth, development and metabolism of a wide variety of cell types and is synthesized and secreted primarily by the liver. Our findings showed that plasma IGF-1 levels increased significantly after treatment with rhGH. The results of RTPCR also showed that rhGH administration obviously promoted the expression of liver IGF-1 mRNA, indicating that rhGH could enhance plasma IGF-1 levels by promoting the expression of liver IGF-1 mRNA. IGF-1 can stimulate regeneration of the intestinal mucosa and maintain its structure and function (16). Chen et al. (17) demonstrated that IGF-1 can prevent intestinal atrophy in septic rats, protect the integrity of intestinal structure and maintain the function of the intestinal mucosa barrier.

$\mathrm{GH}$ is an important anabolic hormone. Some studies have indicated that treatment with GH is safe and beneficial for patients with mild sepsis and severe sepsis, as well as for critically ill patients without sepsis. We have previously demonstrated that rhGH can improve the circulatory function and increase the survival of rats in septic shock (5). However, it has been demonstrated that administration of rhGH to long-stay critically ill adults increases morbidity and mortality (18, 19). At present, the use of rhGH for the treatment of critically ill patients remains controversial and the reason for the varied effects is still unclear.

In the study by Takala's group (18), higher doses of rhGH were used, while in our study the dose administered to rats was equivalent to half the dose administered to Takala's patients. We guess that the reason for the increased morbidity and mortality observed in the study by Takala's group may have been related to dosage. Higher or lower doses of hormone may exert different effects. Higher GH doses may easily result in insulin resistance, hyperglycemia and inhibition of immune function (18). Therefore, we believe that an appropriate dosage of rhGH may be safe and beneficial for critical cases, instead of being harmful.

The present results showed that plasma IGF-1 levels and the expression of liver IGF-1 mRNA were significantly increased in septic rats after treatment with rhGH, indicating that $\mathrm{GH}$ resistance in sepsis did not occur. However, Yumet et al. (20) demonstrated reductions in circulating IGF-1 12 and $24 \mathrm{~h}$ after rhGH administration in septic rats, suggesting that $\mathrm{GH}$ resistance occurred in sepsis. There are two possible explanations for this apparent difference: 1) it might be associated with the sex of rats. In the present study, we selected female rats, while Yumet et al. (20) used male rats. Signal transducers and activators of transcription (STAT5) are required for both basal and GH-induced expression of hepatic IGF-1. The study by Yumet et al. (20) showed that levels of total GHR, Janus kinase (JAK)2, and STAT5 were unchanged in liver from septic rats. However, phosphorylated STAT5 and STAT5 DNA binding were significantly reduced 30 min after $\mathrm{GH}$ administration in liver from septic rats. These findings indicated that sepsis reduced STAT5 phosphorylation and activity in liver as well as plasma IGF-1 following rhGH administration. The study by Venken et al. (21) indicated that estradiol restored down-regulated receptor signaling systems, such as the estrogen receptor alpha and the prolactin receptor. Estradiol thereby recovered the JAK/ STAT pathway as evidenced by a significantly increased activation of the transcription factor STAT5. In the present study, we used female rats, which mainly secrete estrogen. Estrogen is a major GH-independent regulator of hepatic IGF-1 synthesis (21). We assume that, in septic female rats, estrogen may increase activation of the transcription factor STAT5 and the hepatic IGF-1 gene transcription as well as plasma IGF-1 levels following rhGH administration. 2) The 
apparent difference might be related to the dose of rhGH. In the study by Yumet et al. (20), a higher dose of rhGH (1.6 mg/kg) was used, while in our study the dose administered to rats was $2.25 \mathrm{U} / \mathrm{kg}(0.75 \mathrm{mg} / \mathrm{kg})$, which was equivalent to 1 half the dose administered to rats by Yumet et al. (20). However, the regulation of IGF-1 gene expression is controlled by many factors other than JAK/STAT signaling, including the production and activity of transcription factors, recruitment of transcriptional co-activators, IGF-1 mRNA turnover, protein synthesis, and so on. Further studies will be helpful to elucidate the mechanisms involved in the difference.

In conclusion, the present study showed that the integrity of the intestinal mucosa barrier was injured and bacterial translocation occurred in septic rats. Treatment with rhGH exerted beneficial effects by maintaining the function of the intestinal mucosa barrier in septic rats. The possible mechanism might involve the rhGH-inhibited apoptosis of intestinal mucosa cells and the rhGHmaintained intestinal mucosa barrier via the roles of GH and IGF-1.

\section{References}

1. Scopa CD, Koureleas S, Tsamandas AC, Spiliopoulou I, Alexandrides T, Filos KS, et al. Beneficial effects of growth hormone and insulin-like growth factor I on intestinal bacterial translocation, endotoxemia, and apoptosis in experimentally jaundiced rats. J Am Coll Surg 2000; 190: 423-431.

2. Wang $\mathrm{X}$, Wang $\mathrm{B}, \mathrm{Wu} \mathrm{J}$, Wang G. Beneficial effects of growth hormone on bacterial translocation during the course of acute necrotizing pancreatitis in rats. Pancreas 2001; 23: 148-156.

3. Shulman DI. Gastrointestinal effects of growth hormone. Endocrine 2000; 12: 147-152.

4. Darmaun D, Hayes V, Schaeffer D, Welch S, Mauras N. Effects of glutamine and recombinant human growth hormone on protein metabolism in prepubertal children with cystic fibrosis. J Clin Endocrinol Metab 2004; 89: 1146-1152.

5. Huang Y, Wang SR, Yi C, Ying MY, Lin Y, Zhi MH. Effects of recombinant human growth hormone on rat septic shock with intraabdominal infection by E. coli. World J Gastroenterol 2002; 8: 1134-1137.

6. Sulejczak D, Czarkowska-Bauch J, Macias M, Skup M. Bcl-2 and Bax proteins are increased in neocortical but not in thalamic apoptosis following devascularizing lesion of the cerebral cortex in the rat: an immunohistochemical study. Brain Res 2004; 1006: 133-149.

7. Coopersmith CM, Stromberg PE, Dunne WM, Davis CG, Amiot DM, Buchman TG, et al. Inhibition of intestinal epithelial apoptosis and survival in a murine model of pneumonia-induced sepsis. JAMA 2002; 287: 1716-1721.

8. Baixeras E, Jeay S, Kelly PA, Postel-Vinay MC. The proliferative and antiapoptotic actions of growth hormone and insulin-like growth factor-1 are mediated through distinct signaling pathways in the ProB Ba/F3 cell line. Endocrinology 2001; 142: 2968-2977.

9. Balteskard L, Unneberg K, Mjaaland M, Jenssen TG, Revhaug A. Growth hormone and insulinlike growth factor 1 promote intestinal uptake and hepatic release of glutamine in sepsis. Ann Surg 1998; 228: 131-139.

10. Gelato MC. The growth hormone/insulin-like growth factor axis in critical illness. J Pediatr Endocrinol Metab 2000; 13 (Suppl 2): 10231029.
11. Yakar S, Liu JL, Le Roith D. The growth hormone/insulin-like growth factor-I system: implications for organ growth and development. Pediatr Nephrol 2000; 14: 544-549.

12. Holt RI, Simpson HL, Sonksen PH. The role of the growth hormoneinsulin-like growth factor axis in glucose homeostasis. Diabet Med 2003; 20: 3-15.

13. Le Roith $D$, Scavo L, Butler A. What is the role of circulating IGF-I? Trends Endocrinol Metab 2001; 12: 48-52.

14. Onenli-Mungan N, Yildizdas D, Yapicioglu H, Topaloglu AK, Yuksel B, Ozer G. Growth hormone and insulin-like growth factor 1 levels and their relation to survival in children with bacterial sepsis and septic shock. J Paediatr Child Health 2004; 40: 221-226.

15. Smith JR, Benghuzzi H, Tucci M, Puckett A, Hughes JL. The effects of growth hormone and insulin-like growth factor on the proliferation rate and morphology of RAW 264.7 macrophages. Biomed Sci Instrum 2000; 36: 111-116.

16. Ziegler TR, Mantell MP, Chow JC, Rombeau JL, Smith RJ. Gut adaptation and the insulin-like growth factor system: regulation by glutamine and IGF-I administration. Am J Physiol 1996; 271: G866G875.

17. Chen K, Okuma T, Okamura K, Tabira Y, Kaneko H, Miyauchi $Y$. Insulin-like growth factor-I prevents gut atrophy and maintains intestinal integrity in septic rats. J Parenter Enteral Nutr 1995; 19: 119-124.

18. Takala J, Ruokonen E, Webster NR, Nielsen MS, Zandstra DF, Vundelinckx G, et al. Increased mortality associated with growth hormone treatment in critically ill adults. $N$ Engl J Med 1999; 341: 785-792.

19. Teng Chung T, Hinds CJ. Treatment with GH and IGF-1 in critical illness. Crit Care Clin 2006; 22: 29-40.

20. Yumet G, Shumate ML, Bryant DP, Lang CH, Cooney RN. Hepatic growth hormone resistance during sepsis is associated with increased suppressors of cytokine signaling expression and impaired growth hormone signaling. Crit Care Med 2006; 34: 1420-1427.

21. Venken K, Schuit F, Van Lommel L, Tsukamoto K, Kopchick JJ, Coschigano K, et al. Growth without growth hormone receptor: estradiol is a major growth hormone-independent regulator of hepatic IGF-I synthesis. J Bone Miner Res 2005; 20: 2138-2149. 